Chapman University

Chapman University Digital Commons

ESI Publications

Economic Science Institute

$10-7-2017$

\title{
Who's Holding Out? An Experimental Study of the Benefits and Burdens of Eminent Domain
}

\author{
Abel Winn \\ Chapman University,winn@chapman.edu \\ Matthew W. McCarter \\ Chapman University, matthew.mccarter@utsa.edu
}

Follow this and additional works at: https://digitalcommons.chapman.edu/esi_pubs

Part of the Economic Theory Commons, and the Other Economics Commons

\section{Recommended Citation}

Winn, A., \& McCarter, M. (2018). Who's holding out? An experimental study of the benefits and burdens of eminent domain. Journal of Urban Economics, 105, 176-185. doi: 10.1016/j.jue.2017.10.001

This Article is brought to you for free and open access by the Economic Science Institute at Chapman University Digital Commons. It has been accepted for inclusion in ESI Publications by an authorized administrator of Chapman University Digital Commons. For more information, please contactlaughtin@chapman.edu. 


\section{Who's Holding Out? An Experimental Study of the Benefits and Burdens of Eminent Domain}

\section{Comments}

NOTICE: this is the author's version of a work that was accepted for publication in Journal of Urban Economics. Changes resulting from the publishing process, such as peer review, editing, corrections, structural formatting, and other quality control mechanisms may not be reflected in this document. Changes may have been made to this work since it was submitted for publication. A definitive version was subsequently published in Journal of Urban Economics, volume 105, in 2018. DOI: 10.1016/j.jue.2017.10.001

The Creative Commons license below applies only to this version of the article.

\section{Creative Commons License}

\section{(c) 1 (1) 90}

This work is licensed under a Creative Commons Attribution-Noncommercial-No Derivative Works 4.0 License.

\section{Copyright}

Elsevier 


\title{
Who's Holding Out? \\ An Experimental Study of the Benefits and Burdens of Eminent Domain*
}

\author{
By Abel M. Winn and Matthew W. McCarter
}

\begin{abstract}
A substantial literature identifies seller holdout as a serious obstacle to land assembly, implying that eminent domain is an appropriate policy response. We conduct a series of laboratory experiments to test this view. We find that when there is no competition and no eminent domain, land assembly suffers from costly delay and failed assembly; participants lose $18.1 \%$ of the available surplus. Much of the inefficiency is due to low offers from the buyers ("buyer holdout") rather than strategic holdout among sellers. When buyers can exercise eminent domain the participants lose $18.6 \%$ of the surplus. This loss comes from spending money to influence the fair market price and forcing sellers to sell even when the sellers value the property more than the buyer. Introducing weak competition in the form of a less valuable substitute parcel of land reduces delay by $35.7 \%$ and virtually eliminates assembly failure, so that only $11.5 \%$ of the surplus is lost.
\end{abstract}

*** Pre-copy Edited Version ***

To appear in Journal of Urban Economics

October 3, 2017

\footnotetext{
*Abel Winn (corresponding author: winn@ chapman.edu) is an associate professor of managerial economics at Chapman University. Matthew McCarter is an associate professor of management at University of Texas at San Antonio. Portions of this research was completed while the second author was Visiting John Angus Erskine Fellow at University of Canterbury. This research was made possible by the facilities at the Economic Science Institute and generous funding from the International Foundation of Research in Experimental Economics (IFREE Grant \#121). We wish to thank the editor and two anonymous referees for very helpful comments on an earlier draft of this study. All remaining errors - of which we could find none - are our own.
} 


\section{Introduction}

A substantial theoretical literature identifies seller holdout as a significant impediment to efficient land assembly (Calabresi and Malamed 1972, Eckart 1985, Bittlingmayer 1988, Cohen 1991, Epstein 1992, 1993, Strange 1995 and Menezes and Pitchford 2004) and a possible justification for eminent domain (Allen 2000, Miceli and Sirmans 2007, Rose 2011). Suppose, for example, that two landowners with adjoining property each value their own parcel at $\$ 100,000$ and a developer wishes to acquire both parcels. The development is such that both parcels are necessary for its completion. His maximum willingness-to-pay (WTP) is $\$ 0$ for either one of the parcels but $\$ 250,000$ for the pair. This may impede efficient assembly because both sellers are in a position to hold out for a large share of the surplus. Strategic holdout can draw out the bargaining process, causing costly delay or assembly failure. This is especially likely if the negotiating parties face uncertainty about one another's valuations for the land (Shupp, et al. 2013).

The holdout problem in land assembly is a special case of the tragedy of the anticommons (Heller 1998, Buchanan and Yoon 2000, Fennell 2004). An anticommons is a property regime in which multiple agents have the unilateral right to prevent the use of a resource. Examples include water rights transfers (Corbin 2011), assembling pharmaceutical patents (Heller and Eisenberg 1998) and assembling contiguous blocks of the broadcast spectrum (Hazlett 2008, 2014). In each case, too many agents with veto power can hinder a resource's use and reduce economic efficiency.

In the case of land assembly, eminent domain allows a developer to reduce delay and ensure assembly by forcing a recalcitrant landowner to sell her property. However, eminent domain may lead to inefficient assembly and invite influence costs. Inefficient assembly occurs where the sum of the fragmented owners' values for their land exceeds the value of the 
25 development but they are forced to sell. As Munch (1976) points out, the danger of under26 assembly through market mechanisms is mirrored by the danger of over-assembly through 27 eminent domain (see also O'Flaherty, 1994; Miceli and Segerson, 2007; Shavell, 2010).

28 The threat of inefficient assembly is not idle speculation. In the case of Kelo v. New 29 London the Supreme Court upheld the constitutionality of transfering private land to a private 30 developer. The main beneficiary was to be Pfizer, Inc., which would receive a $\$ 300$ million research center. The case was decided in 2005 and seven families were evicted from their

32 property, their houses demolished or moved offsite. Yet the development group never managed 33 to raise financing and gave up the project in 2008. Pfizer left the city of New London the 34 following year. As of 2015 the land where Ms. Kelo and her six neighbors lived remained an 35 undeveloped field.

Eminent domain also imposes influence costs in determining the "fair market value" of

37 the land; i.e., the price that is to be paid to the owner. This price is determined through a legal 38 process in which both the buyer and seller(s) must, at the very least, obtain counsel and pay for 39 separate and independent appraisals of the property. Both sides improve their chances of a 40 favorable price by expending more resources on the legal process relative to their opponent. The result of the legal process is that much of the surplus may be spent influencing the 42 final price. In 2013 the city of Modesto, California used eminent domain proceedings to 43 purchase a portion of one resident's property for $\$ 120,000$. The city spent $\$ 180,000$ in legal fees 44 (Valine 2013). Moreover, more than two decades of experimental work has shown that 45 participants in contests (like a court battle) frequently overspend relative to their Nash 46 Equilibrium strategies. For a survey of the literature, see Dechenaux, Kovenock and Sheremeta 47 (2015). 
A number of experimental studies of land assembly demonstrate that seller holdout does occur and can be costly. (We provide an overview of these results in the following section.) This has led some investigators to suggest that eminent domain may be a necessary tool for efficient land aggregation (Swope, et al. 2011, Cadigan, et al. 2011). However, to date the experimental study of efficiency under a regime of eminent domain versus secure property is limited to a single study (Kitchens and Roomets 2015) that omits several important features of the land assembly problem. Delay in assembly is costless in their experiments, court fees are born only by the buyer and determined exogenously, the court-determined price is known with certainty to all parties and assembly is efficient in all negotiations.

In this paper we provide a comparison between secure property and eminent domain that incorporates inefficient assembly and influence costs. Eminent domain is not efficiency enhancing in our experiments. Participants captured $81.9 \%$ of the available surplus when buyers had no alternative to assembly and no recourse to eminent domain. They captured $81.4 \%$ of the available surplus when buyers could exercise eminent domain and the fair market price was determined by a contest in which both parties could improve their odds of winning by expending more resources. In a third treatment the developer could buy a less valuable substitute parcel of land instead of assembling parcels from the two primary sellers. Participants captured $88.5 \%$ of the available surplus in this treatment.

Interestingly, we find that buyers "hold out" more frequently than sellers. In the baseline treatment with secure property and no competition the sellers rejected a profitable offer in $22.6 \%$ of cases, while $60 \%$ of buyers' final offers were lower than the profit-maximizing offer. The rate of seller holdout was $6.7 \%$ in the treatment with competition and $4.3 \%$ in the treatment with 
70 eminent domain. These rates do not differ statistically; weak competition was as effective at

71 breaking up seller holdout as eminent domain.

\section{II. Prior Studies of Land Assembly}

73 Two empirical papers use land sale data to estimate a premium for assembled land

74 compared to unassembled land. Cunningham (2013) uses GIS maps of Seattle, Washington to

75 identify assemblies that resulted in new construction between 2005 and 2007. He combines this

76 data with sale prices and property characteristics to estimate a hedonic regression. Cunningham

77 (2013) finds that properties that were assembled for new construction sold at a 17\% premium.

78 Yuming, McMillen and Somerville (2016) study the assembly of small parcels in the

79 urban core of Hong Kong between 1991 and 1998. They find that parcels that were redeveloped

80 as part of a land assembly sold for a premium of $8-10 \%$ compared to parcels that were

81 redeveloped individually. The final parcel acquired in an assembly sold for a $12 \%$ premium.

$82 \quad$ Brooks and Lutz (2016) study land assembly in Los Angeles, California between 1999

83 and 2010. They use properties where the existing structure was torn down after sale as a control

84 group against which to compare properties that were assembled. They find that assembly

85 properties sold at a premium of $15 \%$ - $40 \%$ depending on the modelling specification.

These studies are consistent with seller holdout, but they are not conclusive. As Brooks

87 and Lutz (2016) point out, a premium for assembled land proves that there are frictions in land

88 assembly, but those frictions can come from private sources (e.g., holdout and strategic delay) or

89 public sources (e.g., restrictive zoning and building codes). It is not possible to determine how

90 much of the assembly premium is due to holdout with the data that Cunningham (2013),

91 Yuming, MicMillen and Somerville (2016) and Brooks and Lutz (2016) analyze. 
A second difficulty in using field data to study holdout is that sellers who have put their property up for sale (active sellers) likely have lower reservation prices than sellers who have

94 been approached by a developer (passive sellers). A buyer who wishes to redevelop a single 95 property bargains with active sellers and can expect to pay the prevailing market price. But a buyer who needs multiple contiguous properties will almost certainly have to bargain with at

97 least one passive seller, who is in no hurry to sell and values her property above the market price. Thus, assembled properties are likely to have higher reservation prices even in the absence of 99 private frictions.

Laboratory experiments offer a way of observing holdout directly and comparing land assembly under alternative legal frameworks. Several laboratory studies have examined the 102 holdout problem. The most relevant for our research are those by Cadigan, et al. (2009, 2011), 103 Swope, et al. (2011), Collins and Isaac (2012), Parente and Winn (2012), Shupp, et al. (2013), 104 Cadigan, Schmitt and Swope (2014), Zillante, Read and Schwarz (2014), Kitchens and Roomets 105 (2015) and Isaac, Kitchens and Portillo (2016). We summarize these studies in Table 1, listing 106 the treatment variables the authors studied and the primary results. to be infrequent. Across all of the studies in Table 1 there were 3,036 negotiations in which assembly failure could occur. It occurred in 299 (9.8\%) of them. Failure rates were lowest in treatments where there was some competition among the sellers. Cadigan, et al. (2011) 111 conducted experiments in which the assembler negotiated with three landowners but needed only 112 two parcels. Out of 64 groups none failed to assemble the necessary parcels. Parente and Winn 113 (2012) also conducted experiments in which the assembler (represented by the software) needed 114 two parcels and faced three landowners. Out of 768 negotiations where assembly failure was 
115

116

117

118

119

120

121

122

123

124

125

126

127

128

129

130

131

132

133

134

135

136

possible, it occurred only 6 times, a failure rate of $0.8 \%$. Isaac, Kitchens and Portillo (2016) created competition in two ways. First, similar to Cadigan, et al. (2011) and Parente and Winn (2012) they had two treatments in which a buyer faced four sellers but needed to assemble only two or three parcels. Out of 64 negotiations across these treatments assembly failure occurred in only five. In a third competitive treatment the buyer could either assemble all four of the primary parcels or purchase a single parcel from an alternative seller. ${ }^{2}$ In this treatment one negotiation failed out of 28 .

The only experimental study of eminent domain of which we are aware was conducted by Kitchens and Roomets (2015). In their experiments a buyer negotiated sequentially with four sellers who each had a $\$ 4$ private use value for their properties. If he successfully purchased all four parcels the buyer received $\$ 50$ minus the sum of negotiated prices. The sellers were paid the prices they had negotiated if they sold voluntarily. The buyer's and sellers' values were common knowledge. Once a seller agreed to a price it became common knowledge as well.

In one treatment the buyer used contingent contracts. Any seller in the sequence could "walk away" from the negotiations, but this voided all prior contracts. In this case the sellers each received a private use value of $\$ 4$ for their property and the buyer was not paid. In the other treatment all contracts were binding but the buyer could take properties through eminent domain. Each time he invoked eminent domain the buyer paid the seller a predetermined price of $\$ 4$ and paid court fees of $\$ 8.50$. The court fees were parameterized such that if the buyer took all four properties the available gains from trade would be completely consumed.

Kitchens and Roomets (2015) found that prices were roughly the same under contingent contracts and eminent domain. They also found that efficiency was statistically indistinguishable

\footnotetext{
${ }^{2}$ The buyer had the same induced value for assembling the four smaller parcels as for purchasing the larger alternative parcel. This is a key distinction between the design employed by Isaac, Kitchens and Portillo (2016) and our design.
} 
137 across treatments. Participants captured an average of $91.7 \%$ of the available surplus with 138 contingent contracts and $93.2 \%$ with eminent domain. Thus, in their experimental environment 139 and institutions eminent domain was not welfare enhancing.

140 These results are informative and important, but Kitchens' and Roomets' (2015) 141 experimental design omits several features of the land assembly problem. First, they did not 142 incorporate costs of delayed assembly, so assembly failure was the only possible source of 143 inefficiency in their contingent contracts treatment. This is significant because strategic holdout 144 is a dominated strategy in a single-period negotiation with complete information. As noted 145 above, assembly failure does not occur frequently in land assembly experiments, thus the bulk of 146 inefficiency generally comes from costly delay. This omission may positively bias efficiency in 147 Kitchens' and Roomets' (2015) contingent contracts treatment. Second, the buyer's value for the assembled properties was always considerably greater 149 than the sum of the sellers' private use values. Thus, assembly failure posed the largest threat to 150 efficiency, and this could only occur in the contingent contracts treatment. There was no 151 possibility of inefficient assembly in the eminent domain treatment. This may positively bias 152 efficiency in their eminent domain treatment.

Third, buyers and sellers in these experiments faced a known fair market price that was 154 equal to the sellers' private use values. In actual cases of eminent domain the buyer and seller(s) 155 spend money in the courts because they expect to influence the price in their favor. Finally, court costs in Kitchens' and Roomets' (2015) experiments were determined 157 exogenously and fell only on the buyer. In the field sellers often expend resources on the legal 158 process as well, and their levels of expenditure are decision variables. Thus the efficiency of 159 eminent domain is dependent to some extent on whether the two parties spend few resources in 
160

161

162

163

164

165

166

167

168

169

170

171

172

173

174

175

176

177

178

179

180

court or many. Preventing the participants from making this decision on their own could bias efficiency in their eminent domain treatment positively or negatively.

The fact that efficiency may be overstated in the contingent contracts treatment and overstated or understated in the eminent domain treatment makes it difficult to apply Kitchens' and Roomets' (2015) results to policy with high confidence. We introduce an experimental design that incorporates delay costs, inefficient assembly, an uncertain fair market price and endogenous legal expenditures.

\section{[Table 1 Here]}

\section{Experiment Design}

\section{A. Overview of the Negotiation Environment}

Our experiment design is inspired by the work of Shupp et al. (2013), who investigated land assembly under conditions of uncertainty regarding the valuations of the buyer and sellers.

We model an environment in which one buyer negotiates with two owners (the sellers) through a finitely repeated process of offers and responses. ${ }^{3}$ The buyer makes simultaneous independent offers to the sellers, who may accept or reject them.

In our experiments each seller $i$ had a private valuation, $v_{i}$, for his own parcel . Valuations were denominated in "points" that were redeemed for cash at the end of the experiment. The $v_{i}$ were drawn (with replacement) from a discrete uniform distribution with support $[50,100]$ and $E\left(v_{i}\right)=75$. The buyer's WTP for either of the parcels alone was zero, but his WTP for the pair of them was $V$, which was drawn from a uniform distribution with support $[100,250]$ and $E(V)=175$. Note that assembly was efficient in expectation but was

\footnotetext{
${ }^{3}$ Our experiments required the buyer to assemble both parcels to receive a payoff. See Asami (1988) and Asami and Teraki (1990) for models that allows for assembling subsets of the parcels.
} 
181 inefficient with non-zero probability. Agents knew their own valuation but only the distributions 182 from which their counterparts' valuations were drawn.

Negotiation lasted up to 5 periods, which was common knowledge. In each period the

buyer offered a bid, $\beta_{i}$, to each seller who had not yet agreed to sell her parcel. Sellers could only one seller had accepted a bid by the end of period 5 the buyer did not purchase her parcel. accepted their offers in period 1 there was no cost of delay, while the cost was nonzero and monotonically increasing in all subsequent periods.

We tested land assembly within this general negotiation environment in three treatment conditions. In the first (Baseline) the buyer's only profit opportunity was to purchase the parcels from the sellers without recourse to eminent domain. In the second treatment (Competition) the 195 buyer could purchase a substitute parcel of land instead of assembling the fragmented parcels. 196 The substitute was not as valuable to the buyer as the fragmented parcels, however, so that the 197 competitive pressure on the sellers was weak. In the third treatment (Eminent Domain) the buyer 198 could invoke eminent domain and the parcel's price was determined by a Tullock Contest. A 199 high or low price could result from the contest, and a contestant's probability of achieving his 200 preferred price was proportional to the amount of money he spent in the contest.

\section{B. Baseline Treatment: Secure Property}

Participants made their decisions through an electronic computer interface. In the 
204 the sellers' parcels. In the first negotiating period the buyer submitted simultaneous private 205 offers to both sellers. Each seller saw her offer in her square of the matrix and indicated her 206 decision by clicking one of two buttons labelled "accept" and "reject." Once a seller had 207 accepted an offer negotiations for her parcel concluded at the price she had agreed to. If at least 208 one seller had rejected her offer the negotiation went on to the next period. Contracts were 209 contingent; the buyer only paid a seller the agreed price if both sellers accepted an offer.

210 In a single-period negotiation the buyer's optimal strategy is simple to calculate because 211 sellers should accept any offer $\beta_{i} \geq v_{i}$. Since the $v_{i}$ are drawn from the same distribution the 212 buyer has no reason to submit different offers to the two sellers, and so in equilibrium $\beta_{1}=\beta_{2}$. 213 Thus, we omit the subscripts in the following analysis. The buyer's expected profit, $E(\pi)$, is a function of his value and offers:

$$
E(\pi)=(V-2 \beta)\left(\frac{\beta-50}{50}\right)^{2}
$$

216 The first term in (1) is the profit earned by the buyer if both sellers accept and the second term is 217 the probability that his offers exceed both of the their values. Solving the first order condition of 218 (1) for $\beta$ yields the equilibrium bid function:

$$
\beta^{*}=\frac{V+50}{3}
$$

With multiple bargaining periods it becomes difficult to succinctly model buyer behavior

221 after the first period because his best strategy will depend on his beliefs about the sellers.

222 Suppose at least one seller rejects her offer in period one. If the buyer believes that the sellers 223 would only reject an offer that is below their value then in the second period he will incorporate 
224 any accepted offer into the first term of equation (1), substitute the first period $\beta^{*}$ for 50 in its 225 second term and solve for the new equilibrium offer. But if he believes that the sellers are 226 holding out strategically, then he will not change his offers in the second period. A third 227 possibility is that the buyer places a non-zero probability on the sellers rejecting strategically, in 228 which case he will revise his second period offer(s) upward, but by a smaller amount than if he 229 believed them to be sincere.

In their turn, the sellers' optimal behavior depends on their beliefs about the buyers' 231 beliefs. If they believe him to think they are strategic, then strategic holdout will not be 232 profitable because it will incur the delay cost without increasing the buyer's offers in period two. 233 If they believe him to think they will only reject sincerely - i.e., reject offers below their values 234 they will hold out in period 1 so long as the difference in equilibrium offers is greater than $2350.05 v_{i}$

236 The multiplicity of plausible outcomes implies that we cannot predict behavior in the 237 Baseline beyond period 1 with any confidence without knowing the beliefs of the agents. 238 However, earlier empirical work by Zillante, Read and Schwarz (2014) and Shupp, et al. (2013) 239 suggests that offers will rise over time. For the current study we will use the equilibrium offer 240 function as a benchmark for buyer offers in the first period.

\section{Competition Treatment: Secure Property with a Substitute Parcel}

242 In our Competition treatment the buyer faced the two sellers as in the Baseline, but also

243 had the option of buying a substitute parcel of land. The substitute parcel was displayed on 244 participants' screens as a rectangle to the right of the matrix representing the primary parcels. 245 For clarity we will refer to the two fragmented parcels as the "primary parcels" and their owners 246 as the "primary sellers." We will refer to the owner of the substitute parcel as the "alternative 247 seller." The buyer's induced value for the substitute parcel was $80 \%$ of his induced value for 
248 the two primary parcels. The substitute parcel was of no additional value to the buyer if he 249 purchased both of the primary parcels.

250 The buyer initially made his offers to the primary sellers as in the Baseline. If one or 251 both of them rejected his offer, the buyer then submitted an offer to the alternative seller. The 252 delay cost for the period was only incurred if the alternative seller rejected her offer. Contracts 253 were contingent, as above. 255 distribution $[80,160]$ with $E\left(v_{a}\right)=120$. Notice that the expected surplus from assembling the 256 primary parcels was $E(V)-2 E\left(v_{i}\right)=175-150=25$, while the expected surplus from 257 buying the substitute parcel was $0.8 E(V)-E\left(v_{a}\right)=140-120=20$, so purchasing the 258 substitute parcel was not socially optimal on average.

259 We again use the one-period model as our benchmark. If the buyer is forced to make an 260 offer to the alternative seller, his expected profit function is:

$$
E\left(\pi_{a}\right)=\left(0.8 V-\beta_{a}\right)\left(\frac{\beta_{a}-80}{80}\right)
$$

262 Solving the first order condition of (3) for $\beta_{a}$ yields the equilibrium alternative bid function:

$$
\beta_{a}^{*}=0.4 V+40
$$

264 This implies that in equilibrium the buyer's expected profit from dealing with the alternative 265 seller is:

$$
E\left(\pi_{a}^{*}\right)=\frac{(0.4 V-40)^{2}}{80}
$$


Given that failing to assemble the primary parcels will still generate an expected profit of

$E\left(\pi_{a}^{*}\right)$, the buyer's expected profit when he is making an offer to the primary sellers is now:

$$
E(\pi)=(V-2 \beta)\left(\frac{\beta-50}{50}\right)^{2}+E\left(\pi_{a}^{*}\right)\left(1-\left(\frac{\beta-50}{50}\right)^{2}\right)
$$

270 We may solve the first order condition of (6) for $\beta$ to find the equilibrium offer function:

$$
\beta^{*}=\frac{V+50-E\left(\pi_{a}^{*}\right)}{3}
$$

272 Comparing the equilibrium offer functions (2) and (7) we see that the presence of the alternative 273 seller reduces the buyer's equilibrium offers to the primary sellers by one third of the expected 274 profit from dealing with the alternative seller.

Allowing for multiple periods causes equilibrium behavior to become ambiguous for the 276 reasons discussed in the previous section. However, seller holdout was riskier in the 277 Competition treatment due to the risk that the buyer would commit to a contract with the 278 competing party (or parties). Consequently, we expect to see less seller holdout in this 279 environment.

\section{Eminent Domain Treatment}

In the Eminent Domain treatment the buyer was allowed to force a seller who had

282 rejected his offer to sell. This was done by clicking a button labelled "Force Sale" next to a 283 seller's property. If the buyer invoked eminent domain the fair market value was decided 284 through a simulated litigation process. The price the buyer paid was determined by the amount 285 he and the seller spent on litigation. Neither the buyer nor the seller were allowed to spend so 286 much that they could make negative earnings. The most the seller could spend was equal to the 
low price that could result from the contest. The most that the buyer could spend was calculated based on his value and any price he had already agreed to or other contest he was in. This maximum was set so that even if the buyer had to pay the high price in the contest his total expenditures would not exceed his value. The delay cost was incurred at the end of a period only if at least one seller rejected her offer and the buyer did not force her to sell.

If the buyer and seller spent nothing then the fair market value was 50, the lower bound of the seller's value distribution. This is consistent with a prevailing market price of land less than or equal to all landowner's valuations. If one or both spent an amount greater than zero then the fair market price was assessed to be 40 if the buyer won the contest and 60 if the seller won. ${ }^{4}$ The winner was determined probabilistically, with the probability that one contestant wins 297 equal to the amount he spends in the contest divided by the sum of both contestants' spending. 298 Notice that the litigation process effectively offered the buyer and seller a prize equal to 20 , the 299 difference between the high and low prices. We may therefore analyze the legal process as a 300 simple Tullock Contest. It is straightforward to show that with two players the Nash Equilibrium 301 in such a contest is for each party to spend one fourth of the prize (Chowdhury and Sheremeta, 302 2011). Thus, we would expect the buyer and seller to each spend 5 points if the buyer forced a 303 sale. eminent domain in the first place. The buyer knows that if he takes the seller to court the seller's expected profit will be equal to the expected price she will receive minus the amount she spends in court costs. Thus, the buyer's optimal bid offers the sellers an amount that leaves them

\footnotetext{
${ }^{4}$ This range of prices is conservative. Munch (1976) found that eminent domain prices ranged from $28 \%$ below her estimate of market value to more than $100 \%$ above it. More recently, Chang (2010) estimated the fair market value of condemned properties in New York City from 1990 - 2002. He found that for many properties compensation was as low as $50 \%$ below fair market value and as high as $50 \%$ above it.
} 
indifferent between accepting his offer and going to court. Given our parameters this means that $\beta^{*}=45$. Notice this implies that theoretically the threat of eminent domain is sufficient for land assembly. We would therefore expect no forced sales in our Eminent Domain treatment.

\section{E. Procedures}

The parameters of the experiment are summarized in Table 2. Sellers earned their input values even if they did not sell, while buyers only received payment if they assembled both parcels. For this reason we varied the exchange rate between points and dollars by role. Buyers received $\$ 1.00$ for every 2 points, primary sellers $\$ 1.00$ for every 4 points and alternative sellers $\$ 1.00$ for every 7 points due to their higher average input value. These exchange rates ensured that all participants could earn roughly the same cash payment in the experiment. We kept the exchange rates private, but told the participants that their counterparts' exchange rates may be different from their own. The combination of uncertain value draws and private exchange rates made it very difficult for participants to infer their counterpart's earnings. As a result, we would expect other-regarding preferences to be minimized (Cooper and Kagel, 2015).

\section{[Table 2 Here]}

We recruited 150 undergraduate and graduate students at a university in the American Southwest. The participants came from a pool of approximately 2,000 who had signed up in advance to participate in economic experiments. Each participant was in only one treatment. We paid them $\$ 7$ for attending plus earnings that they received from their decisions in the experiment ( $\$ 16.22$ on average). Experimental sessions lasted $30-60$ minutes, including time for instructions.

Participants sat at desks separated by privacy dividers. Each received a half-page summary of the rules of the experiment as well as important parameter information, such as the 
331 distributions from which values would be drawn. An experimenter read the instructions aloud

332 from a script, pausing at predetermined points to elicit questions and answer them. We projected

333 screenshots of the user interface on a screen at the front of the laboratory.

334 We described the decision space as neutrally as possible to focus the participants' 335 attention on their own profit calculations rather than their personal feelings about eminent 336 domain. We called the parcels of land "inputs" that the buyer wished to purchase and referred to 337 a "forced sale" rather than eminent domain or condemnation, and a "contest" rather than a 338 litigation process.

Negotiations in all treatments were strictly private. Sellers never saw one another's offers, nor were they informed whether another seller had accepted her offer except when the buyer succeeded in assembling the primary inputs or bought the alternative input. In the Eminent Domain treatment sellers did not know if the other seller in their group had been forced to sell.

343 When competing in a contest neither contestant was told how much their opponent had spent. 344 Each experiment session consisted of 3 rounds. Each round was a separate negotiation. 345 Participants took the same role in every round, but were matched into different groups. To keep 346 the negotiations independent across rounds we re-matched the participants so that they were 347 never grouped with any of the same counterparts more than once. This prevented participants 348 from rewarding or punishing one another for their decisions in prior rounds. The number of 349 rounds and uniqueness of each round's grouping was common knowledge. After the third round 350 the computer software randomly chose one of the rounds for each participant. The participant 351 was paid according to his earnings in that round's negotiation. To facilitate unique groups we conducted the Baseline and Eminent Domain treatments in 353 sessions with nine participants organized into three groups - three buyers and six sellers. This 
354 allowed us to obtain nine observations from each session. For the Competition treatment every

355 session used twenty participants organized into five groups - five buyers, ten primary sellers and

356 five alternative sellers. This allowed us to obtain fifteen observations per session. We

357 conducted 5 sessions of the Baseline and Eminent Domain treatments and three sessions of the

358 Competition treatment, giving us 45 negotiations for each treatment. (See Table 3.)

[Table 3 Here]

\section{Experiment Results}

\section{A. Benchmark simulations and an overview of results}

We conducted simulations to find the best-case outcomes that could occur in our experiments if buyers submitted their equilibrium offers and sellers did not hold out. In the Baseline and Competition simulations the sellers accepted offers greater than or equal to their values and this was known to the buyers. The simulated buyers responded to rejected offers by

366 revising their offers upward optimally in the subsequent period. In the simulated Eminent Domain treatment sellers always accepted their offers, so that the buyers never invoked eminent domain. For each treatment we used the same parameter draws as those in the experiments with

369 human participants. We recorded the buyers' opening offers, number of negotiating periods, 370 efficiency and the use of eminent domain. This provides us with a benchmark for comparison to 371 the outcomes from our experiments.

Table 4 displays the results of our simulations for each treatment alongside the observed 374 results of our experiments. Participants in the Baseline performed below the benchmark. The 375 average opening offer was less than the average equilibrium offer. This, combined with some 376 holdout among sellers resulted in more delay in the experiments than in our simulations. 
377 Consequently, on average the participants captured only $81.2 \%$ of the available surplus on 396 detail. average, compared to $88.5 \%$ in the simulations.

Outcomes in the Competition treatment were roughly equal to the benchmark. The average opening offer of 64.4 was only $6 \%$ less than the average equilibrium offer of 68.5 . The number of negotiating periods was nearly identical in the simulations and the experiments. On average the participants captured $89.9 \%$ of the available surplus, slightly more than the benchmark of $89.5 \%$.

In the Eminent Domain experiments the buyers' offers were more generous to the sellers than theory would predict. Nevertheless, many sellers did not accept their opening offers, which led to some delay and many instances of forced sales. Across all negotiations $41.1 \%$ of sellers were forced to sell their inputs. The high rate of eminent domain lead to considerable spending to determine fair market prices. The average spending was 15.7 for buyers and 15.9 for sellers, more than triple the equilibrium of 5. This resulted in an average efficiency of $80.6 \%$, compared to $95.1 \%$ in the benchmark simulations.

Notice that in our simulations the Eminent Domain treatment had the highest average efficiency (95.1\%), followed by Competition (89.5\%) and the Baseline (88.5\%). That is, the experimental environment was the most favorable to achieving high levels of surplus with eminent domain. Yet participants in the Eminent Domain treatment of the experiments captured the least of the available surplus. Below we explore the results of our experiments in more

\section{B. Buyer offers}

In Figure 1 we present the average deviation of the buyers' first and final offers from our theoretical predictions for each treatment. In the Baseline treatment the average first period offer 
was 58.6 , which is $22.7 \%$ below the average equilibrium offer of 75.8 . This was not due to a small number of outliers. Of the 45 first offers in the Baseline, 38 (84.4\%) were below the optimal offer given the buyer's value. We compared the first period offers to those in the benchmark simulations with a Wilcoxon sign rank test. The unit of analysis was the average of a buyer's two offers in the first period of the round. We can reject the null hypothesis that first period offers in the Baseline treatment were no different from the equilibrium with high confidence $(p<0.001)$.

\section{[Figure 1 Here]}

The Baseline offers did increase in subsequent periods, but remained overly conservative. The average final offer in the Baseline was 69.5. $60 \%$ of these final offers were below the Nash Equilibrium. A Mann-Whitney test comparing a buyer's final offer of the round with his first offer indicates that the difference is statistically significant $(p<0.001)$. However, even by the end of negotiations the typical buyer in the Baseline offered the sellers $8.3 \%$ less than would have been optimal in the first period (Wilcoxon sign rank test, $p=0.002$ ).

The pattern was similar in the Competition treatment, but not as pronounced as the Baseline. The average buyer's value was 168 points, which implied an average first offer of 68.5. Buyers' offers were 64.4 on average, or approximately $6 \%$ below equilibrium. The difference between optimal and observed offers is marginally statistically significant (Wilcoxon $p=0.059)$ but rather small in economic significance. The average final offer in the Competition treatment was 70.1, which is not statistically different than the equilibrium first-period offer (Wilcoxon, $p=0.592$ ). Overall, $42.2 \%$ of first offers and $22.2 \%$ of final offers were below equilibrium in the Competition treatment. 
Notice that introducing competition among the sellers was predicted to reduce buyers'

423 average offers by 7.3 points. Instead the buyers increased their offers by an average of almost 10

424 points. In the Baseline treatment buyers may have made low offers in an effort to avoid

425 overpaying one of the sellers and thereby constraining their ability to make an adequate offer to

426 the other. In the buyers' minds this risk may have dominated the risk that making low offers

427 would drag out the negotiations and increase the risk of assembly failure. Overpaying a primary

428 seller was less of a concern in the Competition treatment because even if the buyer found himself

429 unable to make a sufficiently high offer to one of the primary sellers he might still negotiate a

430 contract with the alternative seller. Mann-Whitney tests do not find the distributions of first or

431 final offers to be statistically different between the Baseline and Competition treatments $(p=$

4320.263 and $p=0.765$ ). However, we also compared offers in these treatments by performing chi-

433 squared tests of the frequency of offering less than the equilibrium prediction. Buyers in the

434 Baseline were more likely to offer less than the equilibrium in both their first and final offers ( $p$ $435<0.001$ in both cases).

While offers under secure property tended to be too low, under eminent domain the

437 buyers did not fully exploit the strength of their bargaining position. The average first offer was

43856 in the Eminent Domain treatment. This is $24.4 \%$ higher than the equilibrium offer of 45 , and

439 a Wilcoxon sign rank test indicates that the difference is statistically significant $(p<0.001)$. The

440 buyers may have been motivated by fear that sellers would view the equilibrium offer as unfair

441 and reject it to punish them. This would force both sides to spend money in the Tullock Contest,

442 and could be viewed as a form of costly punishment. Henrich, et al. (2006) have shown that the

443 willingness to engage in costly punishment is a feature of a wide range of human societies. 


\section{Seller holdout}

To analyze seller holdout, we found the highest offer that a seller rejected in a round and subtracted her input value from it. Where this normalized highest rejected offer is greater than zero we consider the seller to have withheld her input strategically. The cumulative distributions of the normalized highest rejected offers are shown in Figure 2. A vertical line at the value of zero separates the shares of each distribution that represent strategic rejections from sincere rejections.

\section{[Figure 2 Here]}

Sellers in the Baseline strategically rejected the buyer's offer in $22.6 \%$ of cases. Notice that this is substantially less than the percentage of buyers in the same treatment who made offers that were lower than the equilibrium. $60 \%$ of the buyers' final offers were below equilibrium. If we consider these low offers to be buyer holdout then buyers held out 2.7 times as often as sellers. Moreover, in Section IV d. below we demonstrate that the loss of efficiency from delay was mainly due to buyer holdout. Our findings run counter to the conventional wisdom that sellers are primarily responsible for the difficulties of land assembly.

In the Competition treatment the primary sellers strategically rejected far fewer offers. In $6.7 \%$ of cases a primary seller's highest rejected offer exceeded her value, a $70.4 \%$ reduction compared to the Baseline. A chi-square analysis confirms that holdout was statistically less frequent in the Competition treatment compared to the Baseline $(p=0.013)$. The effect of competition on strategic holdout is especially impressive when we compare it to eminent domain. Sellers in the Eminent Domain treatment rejected profitable offers in $4.3 \%$ of cases. A chi-square test cannot reject the null hypothesis that holdout rates were equal in the Eminent 
467 Domain and Competition treatments $(p=0.609)$. That is, introducing a weak form of 468 competition was just as effective at discouraging seller holdout as eminent domain.

469 D. Efficiency

470 Eminent domain did not increase the gains from trade, but weak competition did. As we 471 noted above average efficiency was highest in the Competition treatment (89.9\%), followed by 472 the Baseline $(81.2 \%)$ and Eminent Domain treatments (80.6\%). We compared the outcomes 473 across treatments with pair-wise Mann-Whitney tests. Efficiency was statistically 474 indistinguishable between the Baseline and Eminent Domain treatment $(p=0.971)$, but it was 475 statistically significantly higher in the Competition treatment than in the Baseline $(p=0.012)$ and 476 Eminent Domain treatments $(p=0.045)$.

[Table 5 Here]

In Table 5 we provide complete information regarding the number of points that could 479 have been earned in each treatment, along with how many points were earned and the number of 480 points that were lost due to the various possible sources of inefficiency. In the Baseline 481 participants failed to capture a total of 1,498 points, or $18.1 \%$ of the available surplus. Of these, 4821,237 points $(82.6 \%)$ were lost due to delay, and $225(15 \%)$ were lost due to assembly failure.

483 We have already noted that both sellers and buyers held out in the form of rejected offers above 484 seller's values and offers below Nash equilibrium. Which form of holdout cost more in terms of 485 lost gains from trade? We addressed this question by simulating two counterfactuals: a no seller 486 holdout $(\mathrm{NSH})$ counterfactual and a no buyer holdout $(\mathrm{NBH})$ counterfactual. For the NSH 487 counterfactual we simulated buyers whose offers were identical to those submitted by the human 
488 buyers and sellers who accepted all offers that were greater than or equal to their value. ${ }^{5}$ This

489 allows us to measure how efficient the negotiations would have been without seller holdout,

490 holding observed buyer decisions constant. We conducted 45 simulations for the NSH

491 counterfactual; one for each negotiation in the experiments.

492

For the NBH counterfactual we simulated buyers who submitted their equilibrium offers

493 and sellers who accepted the offers probabilistically. We constructed an acceptance probability

494 function using the decisions that the human sellers had made in our experiments. For each offer

495 that a human seller had accepted we subtracted the seller's value from the offer to find the

496 normalized accepted offer. The probability that a simulated seller in the NBH counterfactual

497 accepted its offer was equal to the proportion of human sellers who had accepted a normalized

498 offer of equal or lesser value. This allows us to measure how efficient the negotiations would

499 have been without buyer holdout, holding observed seller behavior constant. Due to the

500 probabilistic nature of the simulated sellers' decisions we conducted 1,000 simulations for each

501 negotiation in the experiments, for a total of 45,000.

[Figure 3 Here]

503

Figure 3 displays the average efficiency in the observed Baseline negotiations, as well as

504 those in the NSH and NBH counterfactuals. As the chart makes clear, buyer holdout was more

505 detrimental to efficiency than seller holdout. In the NSH counterfactual the average efficiency

506 was $84 \%$; only 2.8 percentage points higher than the observed Baseline efficiency. For the NBH

507 counterfactual the average efficiency was $90.2 \%$; 9 percentage points higher than the human

508 participants achieved. Both of these differences are statistically significant according to

509 Wilcoxon sign rank tests $(p=0.033$ for $\mathrm{NSH}, p<0.001$ for $\mathrm{NBH})$. Notice that average

\footnotetext{
${ }^{5}$ In some cases sellers in the laboratory experiments accepted offers that were below their values. We replicated these decisions in the NSH counterfactual, so that the simulated sellers never rejected an offer that had been accepted by their human counterparts.
} 
510 efficiency was higher in the $\mathrm{NBH}$ simulations than in our benchmark simulations. This is

511 because the human sellers accepted offers below their values in $52.9 \%$ of cases, most likely to

512 avoid delay costs. As a result, negotiations lasted for an average of 2.8 periods in the NBH

513 simulations versus 3.3 periods in the benchmark simulations. In the NSH simulations and

514 laboratory experiments the average negotiation took 3.9 and 4.2 periods respectively.

515 Participants were able to capture the highest share of the surplus in the Competition

516 treatment. Average efficiency was $89.9 \%$ in the Competition treatment compared to $81.2 \%$ in

517 the Baseline. This was primarily due to a reduction in delay. The average duration was 2.7

518 periods for all Competition negotiations and 2.1 for those where there was positive surplus

519 available from assembly. Wilcoxon sign rank tests indicate that these were not statistically

520 different than the benchmark simulation averages of 3 and 1.8 ( $p>0.25$ in both cases).

521

The buyers in the Competition treatment made a purchase in $93.8 \%$ of negotiations where

522 there were positive gains from trade. They purchased the parcel(s) that generated the higher 523 surplus $65.6 \%$ of the time. For each negotiation where the buyer's purchase generated less

524 surplus than if he had negotiated an agreement with the other seller(s), we calculated the 525 difference in surplus between the two possible contracts. This allows us to determine the 526 opportunity cost in efficiency from purchasing the wrong input(s). The total opportunity cost 527 was 304 points, which is only $2.2 \%$ of the available surplus in the Competition treatment.

Average efficiency was $80.6 \%$ in the Eminent Domain treatment, which is not

529 statistically different than in the Baseline. Delay and failed assembly did not substantially affect

530 efficiency in the Eminent Domain treatment. Only two negotiations failed to result in assembly

531 because the buyer could not afford to force both sellers to sell. In both of these negotiations the 532 sellers valued their inputs more than the buyer, so no points were lost from assembly failure. 
533 The average duration was 1.4 periods for all negotiations and 1.2 periods for negotiations with 534 gains from trade. As a result, only 157 points (1.9\% of available surplus) were lost due to delay. 535 However, spending in the Tullock Contest was more than $200 \%$ higher than predicted. In 536 theory the buyer and seller should both spend 5 points. In fact, buyers spent an average of 15.7 537 points and sellers an average of 15.9 points. These high averages were due in part to very high 538 spending by a few participants. However, median spending was 10 points for both buyers and 539 sellers; $100 \%$ higher than equilibrium. Wilcoxon sign rank tests confirm that spending was 540 statistically higher than equilibrium for buyers and sellers ( $p<0.01$ for both roles). This is 541 consistent with prior studies on spending in Tullock Contests (see Dechenaux, Kovenock and 542 Sheremeta, 2015)

543 Since litigation costs were the main cause of efficiency loss in the Eminent Domain 544 treatment it is reasonable to consider how sensitive our results are to the variance in prices that 545 could result from the contest. Our parameters required the litigated price to be either 40 or 60 ; 546 i.e., $20 \%$ above or below the true fair market value. The litigated price range determines the size 547 of the contest's prize. Consequently, we would expect a direct relationship between the width of 548 the prices and the level of spending.

549 To estimate the sensitivity of our results to the litigated price range we recalculated the 550 efficiency in the Eminent Domain treatment according to two counterfactuals. In both 551 counterfactuals we assumed that the contestants spent a fixed fraction of the prize. This fraction 552 was calculated for each contestant using the observed spending amounts for the numerator and 553 the observed prize (20 points) in the denominator. In one counterfactual (narrow range) we 554 reduced the litigated price range to be $10 \%$ above or below the fair market value. In the second 
555 counterfactual (wide range) we followed the estimates of Chang (2010) that litigated range from $55650 \%$ below fair market value ( 25 points) to $50 \%$ above it (75 points).

558 increased to $87.6 \%$, statistically significantly greater than the Baseline (Mann-Whitney test, $p=$ 559 0.022). This indicates that where courts face less uncertainty over fair market value eminent 560 domain is likely to be more efficient. However, in the wide range counterfactual the average 561 efficiency is $61.4 \%$, which is statistically significantly less than the Baseline (Mann-Whitney 562 test, $p=0.031$ ). Given that the wide range counterfactual is based on empirical estimates, it is 563 reasonable to treat the results of our laboratory experiments as an optimistic comparison of the 564 efficiency of eminent domain versus sovereign property rights. We advise caution in relying on 565 these counterfactual results, however, because they rely on the assumption that spending 566 strategies do not vary with the range of litigated prices.

567 Theoretically, sellers should accept any offer of 45 points or higher, and the average first 568 offer in the Eminent Domain treatment was 56 points. Thus, we would expect litigation to be 569 infrequent, but that was not the case. The buyer invoked eminent domain against at least one 570 seller in $44.4 \%$ of negotiations and against both sellers in $11.1 \%$ of negotiations. As a result, 571 participants spent 1,149 points to influence the fair market price. This accounts for $73.9 \%$ of all 572 points lost in the Eminent Domain treatment and $13.7 \%$ of the maximum available surplus. 573 Notice that this is almost the same amount that was lost due to delay in the Baseline. What 574 eminent domain gave through faster negotiation it took away through influence costs.

\section{V. General Discussion}

The results of these experiments push our understanding about eminent domain and

577 collective action in three ways. First, we find that - contrary to the conventional wisdom - a 
578 large majority of sellers do not hold out even when the buyer has no alternative to assembly or

579 recourse to eminent domain. Rather, in our experiments it was primarily the buyers who held out

580 for an outsized share of the surplus by making offers that were below the profit maximizing

581 level, and buyer holdout was 3 times as costly as seller holdout. It seems a perverse response

582 under such circumstances to give buyers the right to cut short the bargaining process and force

583 the sale of property. The pattern of buyer holdout across the Baseline and Competition

584 treatments suggests that buyers held out to avoid overpaying one seller, leaving them with

585 insufficient funds to offer an acceptable price to the other. If this is the case it suggests that

586 competition among sellers is important not only to break up seller holdout, but to give buyers

587 flexibility in how they achieve assembly, resulting in higher offers.

588 Second, eminent domain did not enhance the efficiency of negotiated outcomes. The 589 surplus that was saved by avoiding delay was spent in litigation costs. One possible policy 590 response would be to curtail or eliminate the degree to which litigants can influence the price of 591 condemned property. Yet such a policy would run directly counter to democratic principles of 592 due process, and it would also open landowners to predatory behavior on the part of government 593 officials. An alternative policy response would be to place a high burden on the party invoking 594 eminent domain to demonstrate that the gains from assembling the properties is very large. 595 Eminent domain ought not to be invoked to achieve modest improvements in land use due to the 596 risk that influence costs will meet or exceed the gains from trade.

597 Third, we find that even weak competition is sufficient to break down seller holdout and 598 improve economic efficiency. When our buyers had an outside option to assembling the primary 599 sellers' parcels, seller holdout was not statistically higher than when the buyers could force a 600 sale. Having an available substitute also increased the buyers' offers relative to the theoretical 
601 equilibrium. The availability of a substitute parcel reduced the duration of negotiations by $602 \quad 35.7 \%$ overall (from 4.2 periods to 2.7 periods) and almost no surplus was lost due to assembly 603 failure. Comparing weak competition to eminent domain, participants captured 7.1 percentage 604 points more of the available surplus under competition.

606 of Cadigan et al. (2011), Parente and Winn (2012) and Isaac, Kitchens and Portillo (2016) that 607 competition among sellers makes land assembly quite easy. Notice that in their studies the 608 sellers competed with perfect substitutes, while in the present study the buyer incurred a $20 \%$ 609 loss in value from buying the alternative parcel. A straightforward implication for policy is that 610 eminent domain should be restricted to cases where the assembling agent has no viable 611 alternative to assembling a single set of properties. An example would be the construction of a 612 road through a mountain range with a single pass. If the land along that pass is owned by 613 multiple parties then eminent domain may be necessary to prevent strategic holdout from 614 thwarting efficient assembly. But suppose there is a second pass that is less suitable for a road, 615 perhaps because it is further from the existing infrastructure or takes a more circuitous route 616 through the mountains. In this case eminent domain is less likely to be justified because an 617 element of competition has been introduced which will break down seller holdout.

618 More broadly, our findings also contribute to the study of the tragedy of the 619 anticommons, of which the land assembly problem is a special case. Legal research conjectures 620 that, without a superordinate authority the tragedy of the anticommons is inevitable. Indeed, 621 scholars have long endorsed placing a superordinate authority over shared resources to navigate 622 social dilemmas (e.g., Hardin 1968, Kollock 1998). Our findings highlight that a superordinate 
623 authority may reduce the negative externalities of seller holdout while imposing externalities of 624 its own.

625 The anticommons literature - and social dilemma research in general - typically assumes 626 that resource management is a closed system with no outside alternatives; e.g., there is only one 627 configuration of land amenable to development or one set of patents that will permit a suitable 628 pharmaceutical treatment. Relaxing this assumption and taking an open system approach to the 629 tragedy of the anticommons, as we have done with land assembly, introduces an effective 630 substitute for superordinate authority.

631 Our study does have some important limitations. First, we did not vary the number of 632 sellers, so we cannot measure how the degree of fragmentation interacts with the results reported 633 here. Cadigan, et al. (2011) have demonstrated that delay is exacerbated and assembly failure 634 more common with a larger numbers of sellers. Future research may benefit from examining 635 whether the number of sellers makes land assembly more challenging, especially if sellers are 636 allowed to form coalitions against prospective buyers. Second, we did not vary environmental 637 parameters, such as the magnitude of delay cost or the duration of the eminent domain process. 638 Varying those parameters could affect the relative efficiencies of our Baseline and Eminent 639 Domain treatments. However, it is worth noting that Kitchens and Roomets (2015) also find that 640 eminent domain does not increase efficiency in experiments that are distinct from our own. 641 Finally, there were no externalities from assembly in our experiments, which may encourage 642 seller holdout (O’Flaherty 1994). Future scholarship may benefit from examining whether the 643 knowledge of positive versus negative externalities to those directly involved in the land 644 assembly impact seller holdouts. 
675

676

677

678

679

680

681

682

683

684

685 686

\section{References}

Allen, Tom. 2000. The Right to Property in Commonwealth Constitutions. Cambridge, UK: Cambridge University Press.

Asami, Yasushi. 1988. "A Game-Theoretic Approach to the Division of Profits from Economic Land Development.” Regional Science and Urban Economics, 18(2), 233-246.

and Akihiro Teraki. "On Sequential Negotiation Procedures: Optimal Negotiation Orders and Land Prices.” Regional Science and Urban Economics, 20(4), 537-556.

Brooks, Leah and Byron Lutz. 2016. "From Today’s City to Tomorrow's City: An Empirical Investigation of Urban Land Assembly.” American Economic Journal: Economic Policy, 8(3), 69-105.

Buchanan, James M. and Yong Yoon. 2000. "Symmetric Tragedies: Commons and Anticommons." Journal of Law and Economics, 43(1), 1-14.

Bittlingmayer, George. 1988. "Property Rights, Progress, and the Aircraft Patent Agreement." Journal of Law and Economics, 31(1) 227-248.

Cadigan, John, Pamela Schmitt, Robert Shupp and Kurtis Swope. 2009. "An Experimental Study of the Holdout Problem in a Multilateral Bargaining Game." Southern Economic Journal, $76(2) 444-457$.

. 2011. "The Holdout Problem and Urban Sprawl: Experimental Evidence." Journal of Urban Economics, 69(1), 72-81.

Cadigan, John, Pamela Schmitt and Kurtis Swope. 2014. "That's My Final Offer! Bargaining Behavior with Costly Delay and Credible Commitment." Journal of Behavioral and Experimental Economics, 49, 44-53.

Calabresi, Guido and A. Douglas Melamed. 1972. "Property Rules, Liability Rules, and Inalienability: One View of the Cathedral.” Harvard Law Review, 85(6), 1089-1128.

Change, Yuen-Chien. 2010. "An Empirical Study of Compensation Paid in Eminent Domain Settlements: New York City, 1990 - 2002.” The Journal of Legal Studies, 39(1), 201-244.

Chowdhury, Subhashish M. and Roman Sheremeta. 2011. "A Generalized Tullock Contest." Public Choice 147(3), 413-420.

Cohen, Lloyd. 1991. "Holdouts and Free Riders.” The Journal of Legal Studies, 20(2), 351-362. 
Collins, Sean and R. Mark Isaac. 2012. "Holdout: Existence, Information, and Contingent Contracting." Journal of Law and Economics, 55(4), 793-814.

Cooper, David and John Kagel. 2015. "Other-Regarding Preferences: A Selective Survey of Experimental Results," in John Kagel and Alvin Roth (eds) The Handbook of Experimental Economics, Volume 2, 217-289.

Corbin, Chris. 2011. "8 Reasons Why Water is Not the Next Gold." The Percolator. Bozeman, MT: Property and Environment Research Center.

Cunningham, Chris. 2013. "Estimating the Holdout Problem in Land Assembly." Federal Reserve Bank of Atlanta Working Paper 2013-19.

Dechenaux, Emmanuel, Dan Kovenock and Roman M. Sheremeta. 2015. “A Survey of Experimental Research on Contests, All-Pay Auctions and Tournaments." Experimental Economics 18(4), 609-669.

Eckart, Wolfgang. 1985. "On the Land Assembly Problem." Journal of Urban Economics 18(3), 364-378.

Epstein, Richard A. 1992. "Exit Rights under Federalism." Law and Contemporary Problems, 55(1), 147-165. . 1993. "Holdouts, Externalities, and the Single Owner: One More Salute to Ronald Coase." Journal of Law and Economics, 36(1), 553-586.

Fennell, Lee Ann. 2004. “Common Interest Tragedies.” Northwestern University Law Review, 98(3), 907-990.

Hardin, Garret. 1968. “The Tragedy of the Commons.” Science, 162(3859), 1243-48.

Hazlett, Thomas W. 2008. "Property Rights and Wireless License Values." Journal of Law and Economics, 51(3), 563-598. . 2014. "Efficient Spectrum Reallocation with Hold-Ups and Without Nirvana." George Mason Law \& Economics Research Paper No. 14-16. Available at SSRN: http://ssrn.com/abstract=2440003 orhttp://dx.doi.org/10.2139/ssrn.2440003

Heller, Michael A. 1998. "The Tragedy of the Anticommons: Property in the Transition from Marx to Markets." Harvard Law Review, 111(3), 621-688.

, and Rebecca S. Eisenberg. 1998. "Can Patents Deter Innovation? The Anticommons in Biomedical Research.” Science, 280(5364), 698-701.

Henrich, Joseph, Richard McElreath, Abigail Barr, Jean Ensminger, Clark Barrett, Alexander Bolyanatz, Juan Camilo Cardenas, Michael Gurven, Edwins Gwako, Natalie 
772

773

774

775

776

Henrich, Carolyn Lesorogol, Frank Marlowe, David Tracer, and John Ziker. 2006. “Costly Punishment Across Human Societies.” Science, 312(5781), 1767-1770.

Isaac, R. Mark, Carl Kitchens and Javier E. Portillo. 2016. "Can Buyer 'Mobility' Reduce Aggregation Failures in Land-Assembly?” Journal of Urban Economics, 95, 16-30.

Kollock, Peter. 1998. "Social Dilemmas: The Anatomy of Cooperation." Annual Review of Sociology, 24, 183-214.

Kitchens, Carl and Alex Roomets. 2015. "Dealing with Eminent Domain.” Journal of Behavioral and Experimental Economics, 54, 22-31.

Menezes, Flavio and Rohan Pitchford. 2004. "The Land Assembly Problem Revisited." Regional Science and Urban Economics, 34(2), 155-162.

Miceli, Thomas J. and C.F. Sirmans. 2007. "The Holdout Problem, Urban Sprawl, and Eminent Domain." Journal of Housing Economics, 16(3), 309-19.

Miceli, Thomas J. and Kathleen Segerson. 2007. American Law and Economics Review, 9(1), 160-174.

Munch, Patricia. 1976. "An Economic Analysis of Eminent Domain.” Journal of Political Economy, 84(3), 473-498.

O'Flaherty, Brendan. 1994. "Land Assembly and Urban Renewal." Regional Science and Urban Economics, 24(3), 287-300.

Parente, Michael L. and Abel M. Winn. 2012. "Bargaining Behavior and the Tragedy of the Anticommons." Journal of Economic Behavior and Organization, 84(2), 475-490.

Rose, Carol. 2011. "The Comedy of the Commons: Custom, Commerce, and Inherently Public Property," R. A. Epstein, Private and Common Property: Liberty, Property, and the Law. New York, NY: Routledge, 285-356.

Shavell, Steven. 2010. "Eminent Domain versus Government Purchase of Land Given Imperfect Information about Owners' Valuations.” Journal of Law and Economics, 53(1), 1-27.

Shupp, Robert, John Cadigan, Pamela Schmitt and Kurtis Swope. 2013. "Institutions and Information in Multilateral Bargaining Experiments." B.E. Journal of Economic Analysis and Policy, 14(1), 485-524.

Strange, William C. 1995. "Information, Holdouts, and Land Assembly." Journal of Urban Economics, 38(3), 317-332. 
777 Swope, Kurtis, Ryan Wielgus, John Cadigan and Pamela Schmitt. 2011. “Contracts,

778 Behavior, and the Land Assembly Problem: An Experimental Study," in R. Mark Isaac and

779 Douglas Norton (eds) Research in Experimental Economics 14, 151-180.

780

781

782

783 Yuming, Fu, Daniel P. McMillen and Tsur Somerville. 2016. "Measuring the Cost of Hold-

784 Out: Size and Sequencing in Land Assembly." Working paper.

785

786

Zillante, Arthur, Dustin C. Read and Peter M. Schwarz. 2014. "Land Aggregation Using

787

Contingent and Guaranteed Payments." Southern Economic Journal, 80(3), 702-727.

788 
Table 1. Summary of laboratory experiments of land assembly and holdout.

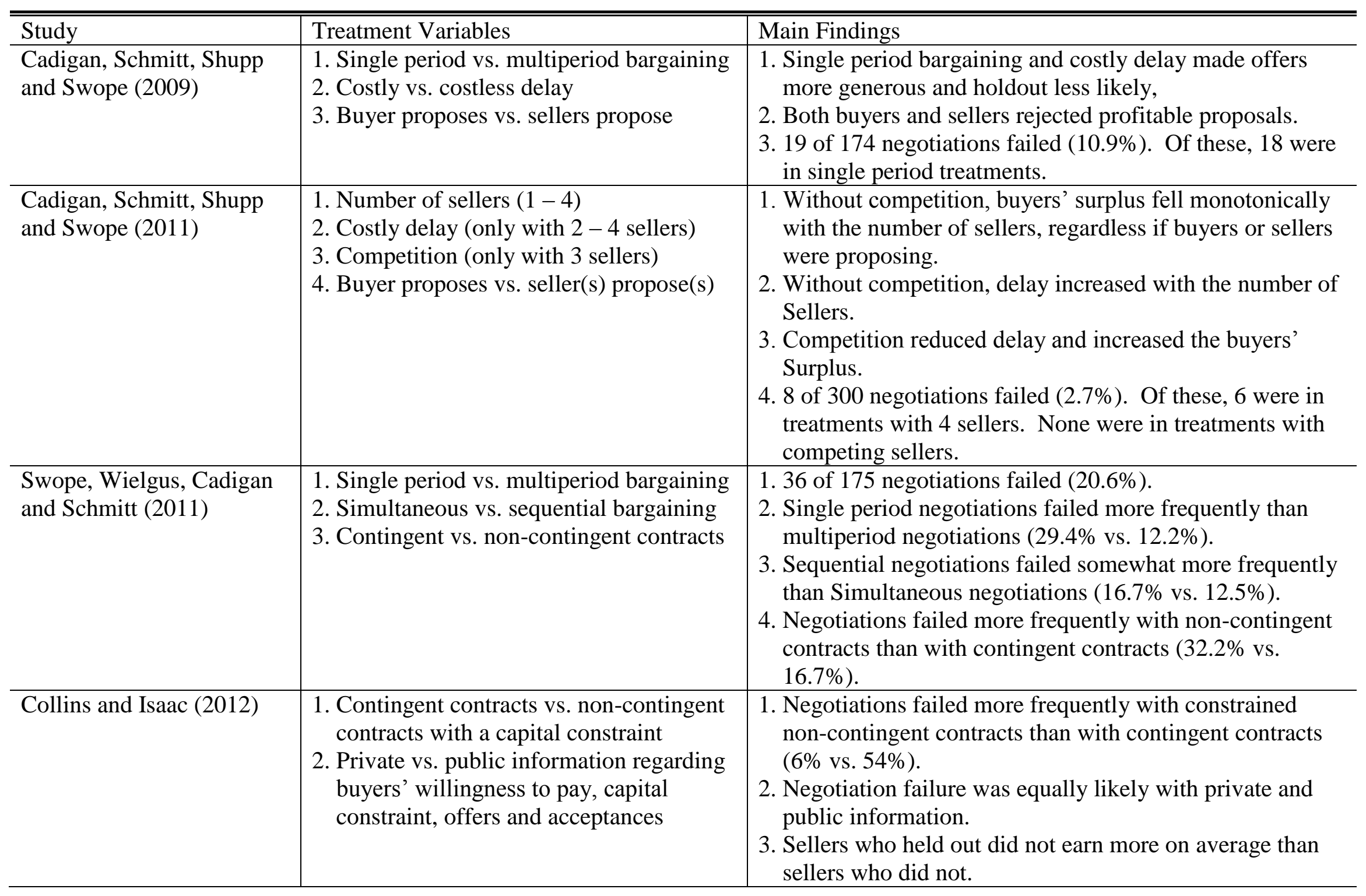




\begin{tabular}{|c|c|c|}
\hline & & $\begin{array}{l}\text { 4. Buyers' expected earnings were equal with contingent } \\
\text { and non-contingent contracts, but variance was lower } \\
\text { with non-contingent contracts. }\end{array}$ \\
\hline Parente and Winn (2012) & $\begin{array}{l}\text { 1. Simultaneous vs. sequential offers to } \\
\text { sellers } \\
\text { 2. Low vs. high vs. uncertain signals of the } \\
\text { buyer's maximum willingness to pay } \\
\text { (WTP) } \\
\text { 3. Strict complementarity ( } 3 \text { of } 3 \text { parcels } \\
\text { must be assembled) vs. partial } \\
\text { complementarity ( } 2 \text { of } 3 \text { parcels must be } \\
\text { assembled) }\end{array}$ & $\begin{array}{l}\text { 1. Final prices were lower with a) simultaneous offers than } \\
\text { sequential offers, b) low signals of WTP than uncertain } \\
\text { or high signals, and c) partial complementarity than full } \\
\text { complementarity. } \\
\text { 2. With strict complementarity } 14 \% \text { of negotiations failed. } \\
\text { Failure rates were lower with sequential offers than } \\
\text { simultaneous offers. } \\
\text { 3. With partial complementarity less than } 1 \% \text { of } \\
\text { negotiations failed. }\end{array}$ \\
\hline $\begin{array}{l}\text { Shupp, Cadigan, Schmitt } \\
\text { and Swope (2013) }\end{array}$ & $\begin{array}{l}\text { 1. Buyer proposes (first) vs. sellers propose } \\
\text { (first) } \\
\text { 2. Persistent proposer role vs. alternating } \\
\text { proposers role } \\
\text { 3. Buyer's value and sellers' costs known } \\
\text { (certain) vs. value and costs drawn from } \\
\text { known distributions (uncertain) }\end{array}$ & $\begin{array}{l}\text { 1. } 7 \text { of } 182(3.8 \%) \text { of negotiations failed. } \\
\text { 2. } 5 \text { of the failed negotiations }(71.4 \%) \text { occurred when } \\
\text { values and costs were uncertain. } \\
\text { 3. Final prices favored the (first) proposer. } \\
\text { 4. Final prices were not significantly different when the } \\
\text { buyer and sellers alternated proposals than when one side } \\
\text { proposed persistently. }\end{array}$ \\
\hline $\begin{array}{l}\text { Cadigan, Schmitt and } \\
\text { Swope (2014) }\end{array}$ & $\begin{array}{l}\text { 1. Buyer proposes vs. sellers propose } \\
\text { 2. Costly vs. costless delay } \\
\text { 3. Symmetric delay costs to the buyer and } \\
\text { sellers vs. delay costs to the buyer only } \\
\text { 4. Multi-round negotiation required vs. } \\
\text { credible commitment to ultimatum offer }\end{array}$ & $\begin{array}{l}\text { 1. Proposing buyers earned more when they had the option } \\
\text { to make an ultimatum offer. Proposing sellers earned } \\
\text { less when they could make an ultimatum offer. } \\
\text { 2. A larger share of surplus went to sellers when delay costs } \\
\text { were asymmetric. } \\
\text { 3. } 16 \text { of } 235 \text { negotiations failed }(6.8 \%) \text {. Of these, } 15 \\
(93.8 \%) \text { were in treatments with asymmetric delay costs. } \\
10 \text { of the failed negotiations }(62.5 \%) \text { were in treatments } \\
\text { where the proposer could make an ultimatum offer. }\end{array}$ \\
\hline $\begin{array}{l}\text { Zillante, Read and Schwarz } \\
\text { (2014) }\end{array}$ & $\begin{array}{l}\text { 1. Contingent contracts vs. contracts with a } \\
\text { contingent payment and a non- } \\
\text { contingent payment (combination) } \\
\text { 2. Buyer's value is known to sellers vs. } \\
\text { buyer's value is unknown to sellers }\end{array}$ & $\begin{array}{l}\text { 1. } 16 \text { of } 66 \text { negotiations failed }(24.2 \%) \text {. Neither of the } \\
\text { treatment variables had a statistically significant effect on } \\
\text { the rate of aggregation. } \\
\text { 2. Sellers rejected the buyers' offers a total of } 712 \text { times. } \\
296 \text { of these rejections }(41.6 \%) \text { were strategic, in that the }\end{array}$ \\
\hline
\end{tabular}




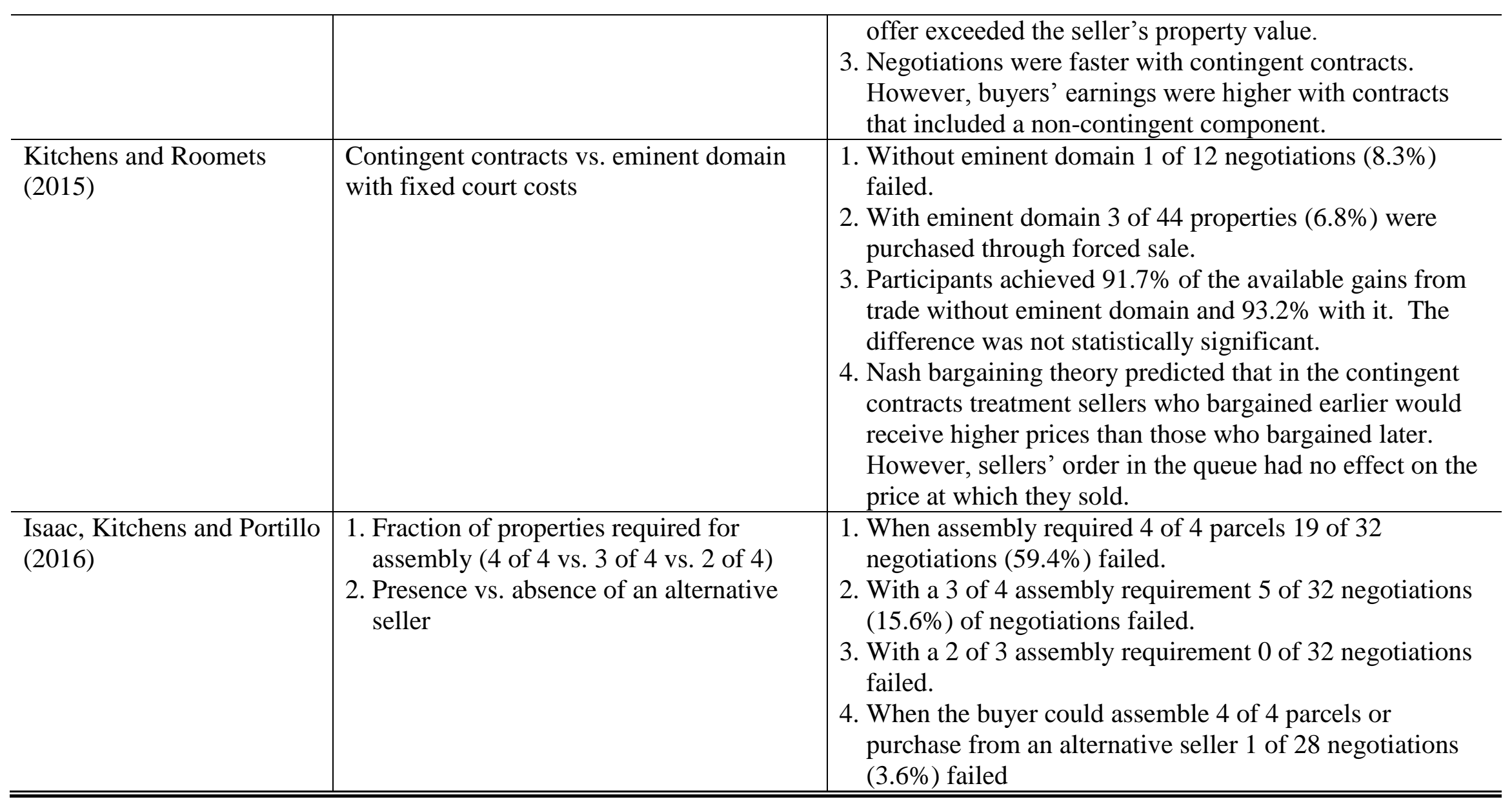


Table 2. Experimental parameters

\begin{tabular}{lc}
\hline \hline Parameter & Value \\
\hline Buyer exchange rate & $\$ 1.00=2$ points \\
Primary seller exchange rate & $\$ 1.00=4$ points \\
Alternative seller exchange rate & $\$ 1.00=7$ points \\
Distribution of primary sellers' values, $v_{i}$ & {$[50,100]$} \\
Distribution of buyer's primary value, $V$ & {$[100,250]$} \\
Buyer's alternative value & $0.8 \mathrm{~V}$ \\
Distribution of alternative seller's value, $v_{a}$ & {$[80,160]$} \\
Negotiating periods & 5 \\
Delay cost per round & $5 \%$ \\
Set of fair market prices in contest & $\{40,50,60\}$ \\
\hline \hline
\end{tabular}

Table 3. Sessions and observations by treatment

\begin{tabular}{lccc}
\hline \hline Treatment & Sessions & Groups per Session & Negotiations \\
\hline Baseline & 5 & 3 & 45 \\
Competition & 3 & 5 & 45 \\
Eminent Domain & 5 & 3 & 45 \\
Total & 13 & -- & 135 \\
\hline \hline
\end{tabular}


Table 4. Outcomes from our benchmark simulations of negotiations alongside observed results from our experiments. We tested for differences between the benchmark and observed outcomes using Wilcoxon sign rank tests for continuous variables (opening offers, number of periods, efficiency and contest spending) and a binomial tests for the percent of sellers forced to sell.

\begin{tabular}{|c|c|c|c|c|c|c|}
\hline \multirow[t]{2}{*}{ Measure } & \multicolumn{2}{|c|}{ Baseline } & \multicolumn{2}{|c|}{ Competition } & \multicolumn{2}{|c|}{ Eminent Domain } \\
\hline & Optimal & Observed & Optimal & Observed & Optimal & Observed \\
\hline Average opening offer & 75.8 & $58.6^{* * * *}$ & 68.5 & $64.4^{\dagger}$ & 45 & $56^{* * * *}$ \\
\hline Average number of periods in all rounds & 3.3 & $4.2^{*}$ & 3.0 & 2.7 & 1 & $1.4^{* * *}$ \\
\hline Average number of periods when assembly produces surplus & 2.3 & $3.75^{* *}$ & 1.8 & 2.1 & 1 & $1.2^{*}$ \\
\hline Average Efficiency & $88.5 \%$ & $81.2 \%{ }^{* *}$ & $89.5 \%$ & $89.9 \%$ & $95.1 \%$ & $80.6 \%{ }^{* * *}$ \\
\hline Percent of sellers forced to sell & -- & -- & -- & - & $0 \%$ & $33.3 \%^{* * *}$ \\
\hline Buyer's average contest spending & -- & -- & -- & -- & 5 & $15.7^{* *}$ \\
\hline Seller's average contest spending & -- & -- & -- & -- & 5 & $15.9^{* * *}$ \\
\hline $\begin{array}{l}\dagger \text { Differs from benchmark at } p \leq 0.10 \\
* \text { Differs from benchmark at } p \leq 0.05 \\
* * \text { Differs from benchmark at } p \leq 0.01 \\
* * * \text { Differs from benchmark at } p \leq 0.001\end{array}$ & & & & & & \\
\hline
\end{tabular}


Table 5. The loss from delay in the Baseline Treatment is similar to the loss from contest spending in the Eminent Domain Treatment

\begin{tabular}{lccc}
\hline \hline & Baseline & Competition & Eminent Domain \\
\hline Points Available & 8,254 & 13,816 & 8,370 \\
Points Achieved & 6,756 & 12,227 & 6,815 \\
& $(81.9 \%)$ & $(88.5 \%)$ & $(81.4 \%)$ \\
Loss from delay & $\mathbf{1 , 2 3 7}$ & 1,114 & 157 \\
& $(\mathbf{1 5 . 0 \% )}$ & $(8.1 \%)$ & $(1.9 \%)$ \\
Loss from failed assembly & 225 & 2 & 0 \\
& $(2.7 \%)$ & $(0.0 \%)$ & $(0.0 \%)$ \\
Loss from inefficient assembly & 36 & 169 & 249 \\
Opportunity cost of inefficient assembly & $(0.4 \%)$ & $(1.2 \%)$ & $(3.0 \%)$ \\
& -- & 304 & -- \\
Loss from contest spending & -- & $(2.2 \%)$ & $\mathbf{1 , 1 4 9}$ \\
Total Loss & & -- & $(\mathbf{1 3 . 7 \%})$ \\
& 1,498 & 1,589 & $(1,555$ \\
\hline \hline
\end{tabular}

Note: Key findings bolded.

Figure 1. Deviation of buyers' average first and final offers from the theoretical prediction

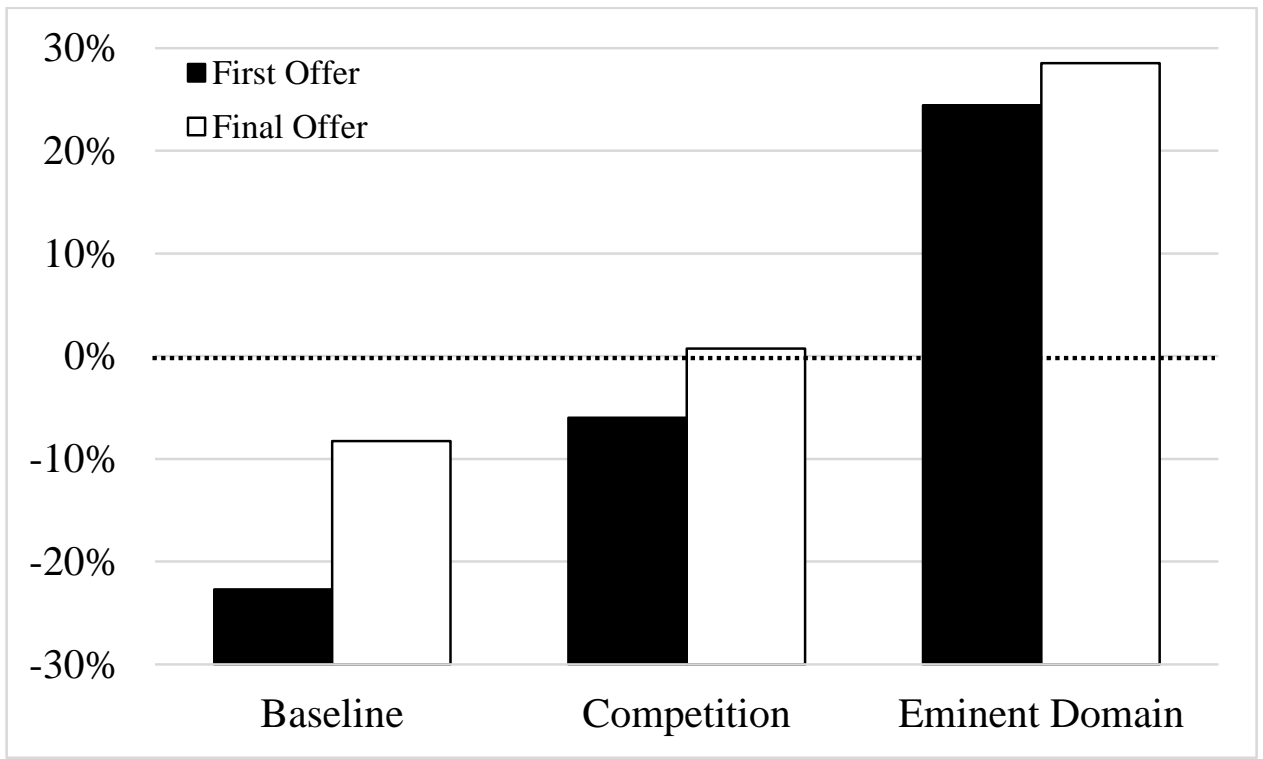


Figure 2. Difference between highest rejected offer and seller's value

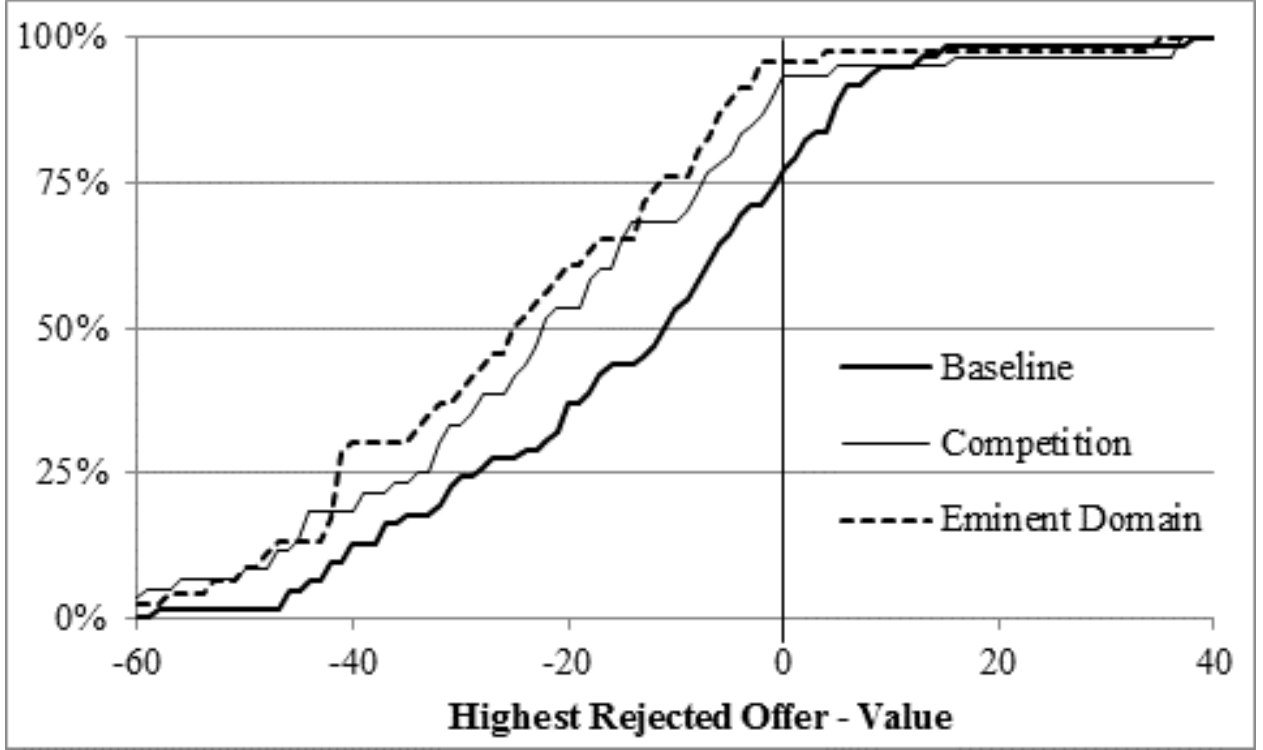

Figure 3. Average efficiency observed in the Baseline treatment and the simulated counterfactuals with no seller holdout and no buyer holdout.

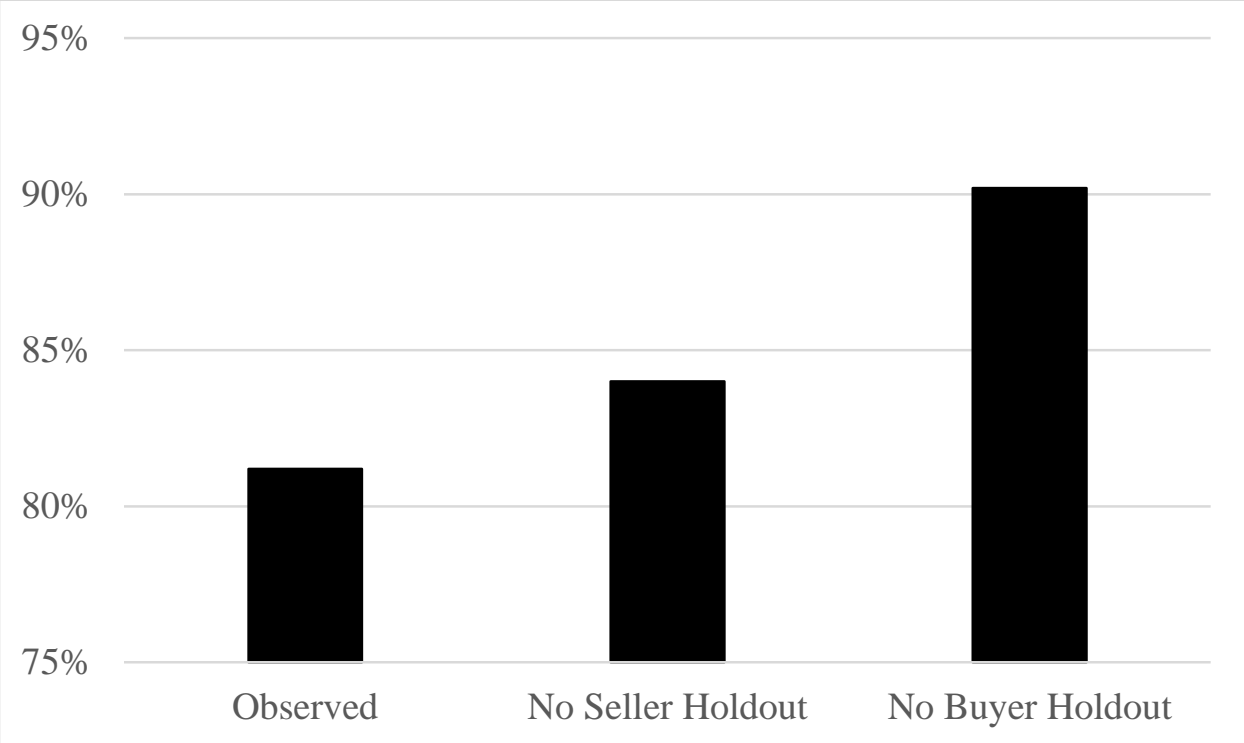

